\title{
Bewegingsstimulering en klachten aan het bewegingsapparaat (deel 2)
}

\author{
J. Heinrich • M.P. Jans • V.H. Hildebrandt
}

\begin{abstract}
In dit literatuuronderzoek is bekeken of bewegingsstimulering arbeidsrelevante klachten aan het bewegingsapparaat (rug- en arm-nek-schouderklachten) kan voorkómen en verminderen. Het blijkt dat overtuigend effect van bewegingsstimulering op dit moment alleen is aangetoond voor de preventie van rugklachten. Daarnaast lijkt een effect op het verminderen van chronische rugklachten erg waarschijnlijk. Bewegingsstimulering lijkt ook het arbeidsverzuim ten gevolge van chronische rug- en arm-nek-schouderklachten te kunnen terugdringen. Verder zijn er wel aanwijzingen voor positieve effecten van bewegingsstimulering op de preventie van armnek-schouderklachten, maar vertonen de beschikbare onderzoeken nog veel inconsistente resultaten. De conclusie is dat bewegingsstimulering een belangrijk middel kan zijn om klachten aan het bewegingsapparaat te voorkómen of te verminderen.
\end{abstract}

Keywords bewegen klachten aan het bewegingsapparaat

Klachten aan het bewegingsapparaat vormen na psychische klachten de belangrijkste oorzaak van ziekteverzuim en arbeidsongeschiktheid. In 2002 waren werknemers met klachten aan het bewegingsapparaat verantwoordelijk voor $27 \%$ van de nieuwe WAO-uitkeringen. ${ }^{1}$ De behoefte aan effectieve interventies om

J. Heinrich $(\bowtie)$

J. Heinrich, M.P. Jans en V.H. Hildebrandt werken bij TNO

Kwaliteit van Leven, Hoofddorp; V.H. Hildebrandt werkt ook

bij Body@Work, Onderzoekscentrum Bewegen, Arbeid en

Gezondheid, TNO VUmc, Amsterdam.Correspondentieadres:

TNO Kwaliteit van Leven, t.a.v. J. Heinrich, Postbus 718,

2130AS Hoofddorp.E-mail: j.heinrich@arbeid.tno.nl. verzuim en uitval van werknemers te voorkómen is de laatste jaren gestegen.

Bewegingsstimulering is een belangrijke component van interventies bij verzuim wegens klachten aan het bewegingsapparaat. Dit in tegenstelling tot interventies die gericht zijn op het voorkómen van klachten aan het bewegingsapparaat: deze bevatten veeleer het implementeren van ergonomische maatregelen en het terugdringen van een ongewenst hoge werkdruk. De laatste tijd is echter bij het voorkómen van klachten aan het bewegingsapparaat toenemende belangstelling voor de mogelijk gunstige effecten van bewegingsstimulering. Het is algemeen bekend dat een lichamelijk actieve leefstijl een gunstig effect heeft op het ontstaan en beloop van tal van chronische ziekten, de levensverwachting ${ }^{2}$ en het arbeidsverzuim. ${ }^{3}$ De vraag is of een lichamelijk actieve leefstijl ook gunstige effecten heeft op arbeidsrelevante aandoeningen.

In een vorig literatuuroverzicht zijn we ingegaan op het effect van bewegingsstimulering op het voorkómen en verminderen van psychische klachten. ${ }^{4}$ Het huidige literatuuroverzicht is een vervolg hierop en beperkt zich tot klachten aan het bewegingsapparaat. Wederom worden de volgende vraagstellingen beantwoord:

1. Wat is er bekend over de relatie tussen bewegen en het ontstaan of verergeren van arbeidsrelevante aandoeningen?

2. Is bewegingsstimulering effectief om arbeidsrelevante aandoeningen te voorkómen en te verminderen?

3 . Is bewegingsstimulering effectief om verzuim vanwege arbeidsrelevante aandoeningen te reduceren c.q. een snelle reïntegratie te bevorderen? 
Tabel 1 Overzicht van opgenomen literatuur

\begin{tabular}{|c|c|}
\hline Soort onderzoek & Auteur en jaar van publicatie \\
\hline \multicolumn{2}{|l|}{ Relatie bewegen en klachten } \\
\hline Review & Hildebrandt et al., $2000^{5}$ \\
\hline Longitudinaal onderzoek & Korhonen et al., $2003^{6}$ \\
\hline Longitudinaal onderzoek & Van den Heuvel et al., $2004^{7}$ \\
\hline \multicolumn{2}{|l|}{ Voorkómen van klachten } \\
\hline Review & Vuori, $2001^{10}$ \\
\hline Review & Linton et al., $2001^{11}$ \\
\hline Systematische review & Proper et al., $2003^{8}$ \\
\hline Systematische review rugklachten & Van Poppel et al., $2004^{12}$ \\
\hline Review arm-, nek-, schouderklachten & Blatter et al., $2004^{13}$ \\
\hline Interventieonderzoek & Proper et al., $2003^{9}$ \\
\hline \multicolumn{2}{|l|}{ Reductie van klachten } \\
\hline Systematische review arm-, nek-, schouderklachten & Konijnenberg et al., $2001^{31}$ \\
\hline Systematische review nek-, schouderklachten & Karjalainen et al., $2001^{42}$ \\
\hline Systematische review arm-, nek-, schouderklachten & Verhagen et al., $2002^{32}$ \\
\hline Review arm-, nek-, schouderklachten & Blatter et al., $2004^{13}$ \\
\hline Review & Gezondheidsraad, $2003^{15}$ \\
\hline Systematische review rugklachten & Van Tulder et al., $2000^{14}$ \\
\hline
\end{tabular}

Systematische review rugklachten

Systematische review rugklachten

Systematische review rugklachten

Interventieonderzoek rugklachten

Interventieonderzoek rugklachten

Interventieonderzoek rugklachten

Interventieonderzoek rugklachten

Arbeidsverzuim

Systematische review arm-, nek-, schouderklachten Systematische review rugklachten

Systematische review rugklachten

Systematische review rugklachten

Review rug-en nekklachten

Systematische review rug-en nekklachten

Systematische review rugklachten

Systematische review rugklachten
Karjalainen et al., $2001^{43}$

Guzmán et al., 200144

Tveito et al., $2004^{45}$

Mannion et al., $1999^{28} 2001^{29}$ Staal, $2003^{20}$ Heymans, $2004^{21}$ Steenstra, $2004^{22}$

Verhagen et al., $2002^{32}$ Van Tulder et al., 2000 ${ }^{14}$ Karjalainen et al., 2001 ${ }^{43}$

Guzmán et al., 2001 44

Linton et al., $2001^{11}$

Schonstein et al., $2003^{35}$

Van Poppel et al., $2004^{12}$

Kool et al., $2004^{36}$

Interventieonderzoek rug-, nek-en schouderklachten

Alle relevante artikelen nvt nvt

Alle relevante artikelen

Takala et al., 1994

Alle relevante artikelen Alle relevante artikelen Alle relevante artikelen nvt

Takala et al., 1994

Ekberg et al., $1994^{34}$

Takala et al., 1994

Takala et al., 1994

Alle relevante artikelen

Seferlis et al., $1998^{16}$ Frost et al., $1995^{23} 1998^{24}$

Lindström et al., $1992^{18}$

Turner et al., $1990^{27}$

Lindström et al., $1992^{18}$

Loisel et al., $1997^{19}$

Alaranta et al., $1994^{17}$

Bendix et al., $1995^{37} 1996^{25}$

Oldervoll et al., $2001^{30}$

nvt

nvt

nvt

nvt

Feuerstein et al., $1993^{41}$

Alle relevante artikelen Lindström et al., $1992^{18}$

Loisel et al., $1997^{19}$

Alaranta et al., $1994^{17}$ Bendix et al., $1995^{37} 199625$

Alle relevante artikelen

Lindström et al., $1992^{18}$

Loisel et al., $1997^{19}$

Alle relevante artikelen

Alaranta et al., $1994^{17}$ Bendix et al., $1995^{37} 1996^{25}$

$1998^{26}$

Hagen et al., $2000^{39}$

Lindström et al., $1992^{18}$

Skouen et al., $2002^{38}$ 


\section{METHODE}

Voor een uitvoerige beschrijving van de methode van dit narrative review wordt verwezen naar een eerder literatuuroverzicht. ${ }^{4}$

Voor dit literatuuroverzicht is gezocht naar de meest recente reviews uit de periode 1994-2004 die betrekking hebben op bewegingsstimulering ter voorkoming of vermindering van klachten aan het bewegingsapparaat. Vervolgens zijn de reviews en de daarin opgenomen artikelen geselecteerd die voldoen aan de eerder vermelde definitie van bewegen. ${ }^{4}$ Naast reviews is ook gezocht naar recente artikelen over dit onderwerp uit de periode 2000-2004. Tabel 1 geeft een overzicht van de reviews en artikelen die zijn opgenomen. Voor de zoekactie is de database van Medline geraadpleegd met de volgende trefwoorden: physical exercise, physical activity, daily activity, training, exercise, leisure time activity, sports participation, sport, fitness, musculoskeletal complaints/pain/disorders/ symptoms, upper limb disorders, back complaints/pain/disorders/symptoms. Bij het formuleren van de resultaten hebben we bij de eerste paragraaf meer waarde gehecht aan longitudinale onderzoeken dan aan cross-sectionele onderzoeken. Bij alle paragrafen hebben we vooral waarde gehecht aan (recente) reviews en recente onderzoeken. Bij de paragrafen over interventies hebben we daarnaast meer waarde gehecht aan gerandomiseerde interventieonderzoeken dan aan gecontroleerde interventieonderzoeken.

\section{RESULTATEN}

Relatie tussen bewegen en klachten

In een review naar de relatie tussen lichamelijke activiteit en klachten aan het bewegingsapparaat is geconcludeerd dat de literatuur inconsistente resultaten laat zien. Sommige onderzoeken toon -den dat lichamelijke activiteit samenhangt met een lagere kans op rug- en nekklachten.

${ }^{5}$ Uit een longitudinaal onderzoek bleek dat bij beeldschermwerkers de frequentie van sporten geen relatie heeft met nekklachten. ${ }^{6}$ Een ander longitudinaal onderzoek toonde aan dat sportende werknemers een kleinere kans hebben op het krijgen van nek- en schouderklachten. ${ }^{7}$

Op basis van inconsistente resultaten uit één review en enigszins tegenstrijdige resultaten uit twee recente onderzoeken, concluderen we dat het lijkt alsof bewegen gerelateerd kan zijn aan minder klachten.

Interventies gericht op het voorkómen van klachten

Er is sterk bewijs dat bedrijfsbewegingsprogramma's met cardiovasculaire training een preventief effect hebben op klachten aan het bewegingsapparaat in het algemeen. ${ }^{8}$ In een recent onderzoek naar de effectiviteit van individuele counseling gericht op bewegingsstimulering werd echter geen effect gevonden op klachten. ${ }^{9}$

Voor rugklachten is sterk bewijs dat lichamelijke activiteit in de vrije tijd een preventief effect heeft. ${ }^{10}$ Ook is er sterk bewijs dat bedrijfsbewegingsprogramma's met cardiovasculaire training een preventief effect hebben op rugklachten. ${ }^{11,12}$ Voor klachten van arm-nek-schouder is geen onderzoek verricht naar het preventieve effect van bewegingsstimulering op een matig intensief niveau of sporten. Bovendien is er beperkt en tegenstrijdig bewijs over de effectiviteit van bedrijfsbewegingsprogramma's op het voorkómen van arm, nek- en schouderklachten ${ }^{13}$

We concluderen dat er sterk bewijs is voor de effectiviteit van bewegingsstimulering op klachten aan het bewegingsapparaat in het algemeen (sterk positief bewijs uit één review en negatieve resultaten uit één onderzoek) en op rugklachten in het bijzonder (sterk bewijs uit drie reviews). Op basis van één review blijkt er beperkt en tegenstrijdig bewijs voor de effectiviteit op klachten van arm nek-schouder.

Bewegingsstimulering kan een belangrijk middel zijn om klachten aan het bewegingsapparaat te voorkómen of te verminderen.

Overtuigend positief effect van bewegingsstimulering is op dit moment alleen aangetoond voor de preventie van rugklachten.

| Er zijn nog veel kennislacunes die het moeilijk maken tot eenduidige conclusies te komen.

Interventies gericht op reductie van klachten

Voor acute lage rugklachten is er sterk bewijs dat specifieke oefeningen niet zinvol zijn ${ }^{14,15}$ In slechts één onderzoek vormde cardiovasculaire training een onderdeel van de interventie. Deze interventie bleek niet effectiever dan behandeling door de huisarts. ${ }^{16}$

Bij chronische lage rugklachten is er sterk bewijs dat een oefenprogramma in het algemeen effectiever is dan behandeling door de huisarts. ${ }^{15}$ Beperken we ons tot de oefenprogramma's waar cardiovasculaire training een onderdeel is, dan is de conclusie minder duidelijk. In wat oudere onderzoeken bij verzuimende werknemers had een dergelijk oefenprogramma een positief effect op pijn of functionele status. ${ }^{17}{ }^{19}$ In recente onderzoeken werden echter geen statistisch significant positieve effecten gevonden, ${ }^{20}{ }^{22}$ soms wel een positieve trend. ${ }^{20}$ Onderzoeken onder patiënten met chronische lage rugklachten lieten vaker een positief ${ }^{23}-^{25}$ dan een negatief ${ }^{26}$ beeld zien. In slechts enkele onderzoeken bij chronische lage rugklachten is het effect van bewegingsstimulering 
op zich bekeken. Een programma met wandelen en joggen bleek geen effect te hebben. ${ }^{27}$ Twee andere onderzoeken toonden aan dat cardiovasculaire training wel een effect heeft op functionele status ${ }^{28,29}$ en pijn. ${ }^{30}$ Uit reviews over interventies bij arm-, nek- en schouderklachten bleek dat er onvoldoende bewijs is dat oefentherapie effectiever is dan geen behandeling. ${ }^{13}, 15,31,32 \mathrm{Er}$ zijn echter slechts twee onderzoeken uitgevoerd waarin cardiovasculaire training een onderdeel van de interventie vormde. ${ }^{33,34}$ Takala et al. vonden dat een bedrijfsbewegingsprogramma voor werknemers met nekklachten geen statistisch significant effect had op functionele status. ${ }^{33}$ Ook Ekberg et al. vonden geen verschillen tussen een multidisciplinaire interventie met cardiovasculaire training en de gebruikelijke zorg bij mensen met nek- of schouderklachten. ${ }^{34}$

We concluderen dat er slechts drie onderzoeken zijn met bewegingsstimulering als enige component van de behandeling. Hiervan zijn twee onderzoeken puur gericht op cardiovasculaire training en zij tonen een positief effect bij mensen met chronische rugklachten. Bij nek- en schouderklachten concluderen we op basis van twee onderzoeken met negatieve resultaten dat er aanwijzingen zijn dat er geen effect is. Veel meer onderzoeken zijn verricht naar het effect van oefenprogramma's waar cardiovasculaire training één van de onderdelen van het programma vormt. Bij acute rugklachten concluderen we op basis van één onderzoek dat er een aanwijzing is dat deze oefenprogramma's geen effect hebben. Bij chronische rugklachten met verzuim concluderen we tegenstrijdig bewijs doordat uit drie enigszins gedateerde onderzoeken positieve resultaten worden gevonden en uit drie recente onderzoeken negatieve resultaten. Tellen we ook de resultaten mee uit onderzoeken waar alleen naar klachten is gekeken dan stellen we vast dat er vaker wel (zes onderzoeken) dan geen effect (vier onderzoeken) is gevonden.

Interventies gericht op arbeidsverzuim

Rondom verzuimreductie bij patiënten met lage rugklachten zijn twee recente reviews verschenen. ${ }^{35,36}$ Schonstein et al. concludeerden dat fysieke oefenprogramma's met cardiovasculaire training bij werknemers met chronische lage rugklachten effectief zijn in het verminderen van het aantal dagen verzuim. ${ }^{35}$ Volgens Kool et al. verminderden interventies met oefentherapie het verzuim bij patiënten met subacute of chronische lage rugklachten. ${ }^{36}$ Dit positieve effect was vooral aanwezig in het eerste jaar na de behandeling en het effect was groter bij patiënten die ernstig beperkt zijn in hun functioneren. Deze conclusies golden ook voor de interventies met een cardiovasculaire component ${ }^{26,37,38}$ en de interventie waarin onder meer het advies gegeven werd om dagelijks te gaan wandelen. ${ }^{39}$ Recentelijk zijn vier onderzoeken over lage rugklachten afgerond die nog niet zijn opgenomen in bovenstaande reviews. In het onderzoek van Staal was het 'graded activity' programma effectief in het terugdringen van het aantal dagen verzuim in vergelijking met gebruikelijke zorg. ${ }^{20}$ Heymans vond geen effect van het 'graded activity' programma op werkhervatting ten opzichte van een laagintensieve rugschool of gebruikelijke zorg. ${ }^{21}$ Steenstra concludeerde dat het 'graded acti-vity' programma terugkeer naar werk juist vertraagde, maar in dit onderzoek was de uitval in het 'graded activity' programma groot. ${ }^{22}$ Uit het onderzoek van Storro et al. bleek dat een multidisciplinaire behandeling met cardiovasculaire training een positief effect heeft op werkhervatting. ${ }^{40}$ Over $\mathrm{arm}$-, neken schouderklachten zijn drie onderzoeken gevonden die een multidisciplinaire behandeling waaronder cardiovasculaire training vergelijken met gebruikelijke zorg ten aanzien van het effect op verzuim. ${ }^{34,40,41}$ Twee onderzoeken rapporteerden een positief effect bij patiënten met chronische arm-, nek of schouderklachten. ${ }^{40,41}$ In het derde onderzoek bleek de multidisciplinaire interventie bij patiënten met acute of subacute nek-schouderklachten werkhervatting te vertragen. ${ }^{34}$

We stellen vast dat er geen onderzoeken zijn verricht met bewegingsstimulering als enige component van de behandeling, maar wel onderzoeken waarin cardiovasculaire training een onderdeel van de interventie vormt. De conclusie is dat deze interventies over het algemeen tot verzuimreductie leiden bij patiënten met chronische rugklachten hoewel onomstotelijk bewijs ontbreekt (twee positieve reviews en additioneel twee positieve en twee negatieve onderzoeken). Voor arm-, nek- of schouderklachten zijn we van mening dat er voor chronische klachten voorzichtige aanwijzingen zijn voor een effect (twee positieve onderzoeken), terwijl voor acute klachten één onderzoek geen effect aantoont (aanwijzing geen effect).

\section{DISCUSSIE EN CONCLUSIE}

Dit narrative review brengt de huidige kennis omtrent de rol van bewegingsstimulering op het voorkómen en verminderen van klachten aan het bewegingsapparaat in kaart. Uit dit review blijken dezelfde kennislacunes naar voren te komen als bij het review naar psychische klachten, ${ }^{4}$ waardoor het moeilijk is tot eenduidige conclusies te komen:

bewegingsstimulering is veelal onderdeel van een bredere interventie, waardoor de bijdrage van bewegingsstimulering moeilijk te bepalen is; 
het type bewegingsstimulering is vaak slecht omschreven in termen van frequentie, duur en intensiteit van beweging, waardoor moeilijk is vast te stellen welke vorm van bewegen het meest effectief is;

| onderzoekspopulaties voor de interventies verschillen sterk tussen onderzoeken;

| uitkomstmaten verschillen sterk tussen onderzoeken;

| duur van de interventie- en follow-up periode verschillen sterk tussen onderzoeken;

| interventies in de controlegroepen verschillen tussen onderzoeken.

In tabel 2 wordt desondanks aangegeven wat we concluderen op basis van de beschikbare literatuur. Alleen van bewegingsstimulering voor de preventie van rugklachten is overtuigend effect aangetoond. Daarnaast lijkt een effect op het verminderen van chronische rugklachten erg waarschijnlijk. Bewegingsstimulering lijkt ook het arbeidsverzuim ten gevolge van chronische rugen arm-nek-schouderklachten te kunnen terugdringen. Verder zijn er wel aanwijzingen voor positieve effecten van bewegingsstimulering op de preventie van arm-nekschouderklachten, maar vertonen de beschikbare onderzoeken veel inconsistente resultaten. Ook dit literatuuroverzicht betreft een narrative review. Voor een beschrijving van de beperkingen van deze opzet wordt verwezen naar het artikel over bewegingsstimulering in relatie tot psychische klachten. ${ }^{4}$

Tabel 2 Effectiviteit van lichamelijke activiteit op het voorkómen van klachten aan het bewegingsapparaat, de reductie van klachten en het arbeidsverzuim

\begin{tabular}{|c|c|c|}
\hline & Klachten a & vegingsapparaat \\
\hline & Rugklachten & $\begin{array}{r}\text { Arm-, nek-, en } \\
\text { schouderklachten }\end{array}$ \\
\hline $\begin{array}{l}\text { Relatie bewegen- } \\
\text { klachten }\end{array}$ & $+/ 0$ & $+/ 0$ \\
\hline $\begin{array}{l}\text { Voorkómen van } \\
\text { klachten }\end{array}$ & ++ & $+/ 0$ \\
\hline Reductie van & acuut: (0) & acuut:? \\
\hline & $\begin{array}{r}\text { chronisch: } \\
+\end{array}$ & chronisch: (0) \\
\hline Arbeidsverzuim & acuut:? & acuut: (0) \\
\hline & $\begin{array}{r}\text { chronisch: } \\
+\end{array}$ & chronisch: + \\
\hline++ : bewezen po & effect van bew & ulering. \\
\hline $\begin{array}{l}+: \text { aanwijzingen } \\
\text { lacunes in bewijsv }\end{array}$ & $\begin{array}{l}\text { positief effec } \\
\text { g. }\end{array}$ & regingsstimulering, \\
\hline $\begin{array}{l}+/ 0 \text { : in sommige } \\
\text { lering, in andere } \\
\text { bewijs. }\end{array}$ & $\begin{array}{l}\text { rzoeken positie } \\
\text { rzoeken geen }\end{array}$ & $\begin{array}{l}\text { n bewegingsstimu- } \\
\text { anes in uiteindelijk }\end{array}$ \\
\hline $\begin{array}{l}\text { (0): aanwijzingen } \\
\text { nes in bewijsvoeri }\end{array}$ & geen effect van & sstimulering, lacu- \\
\hline
\end{tabular}

Combineren we de resultaten uit beide literatuuroverzichten dan blijkt dat bewegingsstimulering voor de twee grote uitvalscategorieën binnen de werkende bevolking zeker perspectieven biedt. Ondanks veel onduidelijkheden, lijkt bewegingsstimulering als interventicum effectief. Bewegen is een reeds veel toegepast middel als het gaat om reductie van klachten aan het bewegingsapparaat of psychische klachten. Uit onze analyse blijkt dat het ook als preventicum van de betrokken arbeidsgerelateerde aandoeningen alle aandacht verdient. Stimulering van bewegen binnen het bedrijf heeft daarmee dus een veel bredere betekenis dan alleen het bevorderen van fitheid en gezondheid in algemene zin.

Belangenconflicten: geen gemeld Financiële ondersteuning: ministerie van Volksgezondheid, Welzijn en Sport

\section{LITERATUUR}

Uitvoering Werknemersverzekeringen. Informatie sociale verzekeringen naar sectoren. Amsterdam: UWV, 2002.

US Department of Health and Human Services (USDHHS). Physical activity and health: a report of the Surgeon General. Atlanta: USDHHS, Centers for Disease Control and Prevention, National Center for Chronic Disease Prevention and Health Promotion, 1996.

Heuvel SG van den, Boshuizen HC, Hildebrandt VH, et al. Sporten, type werk, arbeidsverzuim en welbevinden: resultaten van een 3-jarige follow-up studie. TSG 2003; 5: 256-264.

Heinrich J, Jans MP, Hildebrandt VH. Kan bewegingssti-mulering psychische klachten voorkómen en vermin-deren? (deel 1). Tijdschr Bedrijfs Verzekeringsgeneeskd 2005; 13: 367-370.

Hildebrandt VH, Bongers PM, Dul J, et al. The relations-hip between leisure time, physical activities and musculoskeletal symptoms and disability in worker populations. Int Arch Occup Environ Health 2000; 73: 507-518.

Korhonen T, Ketola R, Toivonen R, et al. Work related and individual predictors for incident neck pain among office employees working with video display units. Occup Environ Med 2003; 60: 475-482.

Heuvel SG van den, Heinrich J, Jans MP, et al. The effect of physical activity in leisure time on neck and upper limb symptoms. Prev Med 2005; 41: 260-267.

Proper KI, Koning M, Beek AJ van der, et al. The effectiveness of worksite physical activity programs on physical activity, physical fitness, and health. Clin J Sport Med 2003; 13: 106-117.

Proper KI, Hildebrandt VH, Beek AJ van der, et al. Effect of individual counseling on physical activity fitness and health. Am J Prev Med 2003; 24: 218-226.

Vuori IM. Dose-response of physical activity and low back pain, osteoarthritis, and osteoporosis. Med Sci Sports Exerc 2001; 33: S551-586.

Linton SJ, Tulder MW van. Preventive interventions for back and neck pain problems: what is the evidence?Spine 2001; 26: 778 787.

Poppel MNM van, Hooftman WE, Koes BW. An update of a systematic review of controlled clinical trials on the primary prevention of back pain at the workplace. Occup Med 2004; 54: $345-352$. 
Blatter BM, Bongers PM, Dieën JH van, et al. RSI-maatregelen: preventie, behandeling en reïntegratie. Den Haag: Ministerie van Sociale Zaken en Werkgelegenheid, 2004.

Tulder M van, Malmivaara A, Esmail R, et al. Exercise therapy for low back pain. Spine 2000; 25: 2784-2796.

Gezondheidsraad. Oefentherapie. Den Haag: Gezondheidsraad, 2003; publicatie nr 2003/22.

Seferlis T, Nemeth G, Carlsson AM, et al. Conservative treatment in patients sick listed for acute low back pain: a prospective randomised study with 12 months' follow-up. Eur Spine J 1998; 7: 461-470.

Alaranta H, Rytökoski U, Rissanen A, et al. Intensive physical and psychosocial training program for patients with chronic low back pain. Spine 1994; 19: 1339-1349.

Lindström I, Ohlund C, Eek C, et al. The effect of graded activity on patients with subacute low back pain. Phys Ther 1992; 72: 279-293.

Loisel P, Abenhaim L, Durand P, et al. A population-based, randomized clinical trial on back pain management. Spine 1997; 22: 2911-2918.

Staal B. Low back pain, graded activity and return to work. Academisch proefschrift. Amsterdam: VU, 2003.

Heymans, MW. The cost-effectiveness of back schools in occupational care, the BOC study. Academisch proefschrift. Amsterdam: VU, 2004

Steenstra I. Back pain management in Dutch occupational health care. Academisch proefschrift. Amster-dam: TNO VUmc, 2004.

Frost H, Klaber Moffett JA, Moser JS, et al. Randomised controlled trial for evaluation of fitness programme for patients with chronic low back pain. BMJ 1995; 310: 151-154.

Frost H, Lamb SE, Klaber Moffett JA, et al. A fitness programme for patients with chronic low back pain. Pain 1998; 75: 273279.

Bendix AF, Bendix T, Vaegter K, et al. Multidisciplinary intensive treatment for chronic low back pain. Clev Clin J Med 1996; 63: 62-69.

Bendix AE, Bendix T, Haestrup C, et al. A prospective, randomized 5-year follow-up study of functional restoration in chronic low back pain patients. Eur Spine J 1998; 7: 111-119.

Turner JA, Clancy S, McQuade KJ, et al. Effectiveness of behavioral therapy for chronic low back pain. J Consult Clin Psychol 1990; 58: 573-579.

Mannion AF, Müntener M, Taimela S, et al. A randomized clinical trial of three active therapies for chronic low back pain. Spine 1999; 24: 2435-2448.

Mannion AF, Müntener M, Taimela S, et al. Comparison of three active therapies for chronic low back pain. Rheumatology 2001; 40: 772-778.

Oldervoll LM, Ro M, Zwart JA, et al. Comparison of two physical exercise programs for the early intervention of pain in the neck, shoulders and lower back in female hospital staff. J Rehabil Med 2001; 33: 156-161.

Konijnenberg HS, Wilde de NS, Gerritsen AA, et al. Conservative treatment for repetitive strain injury. Scand J Work Environ Health 2001; 27: 299-310.

Verhagen AP, Bierma-Zeinstra SMA, Karels C, et al. Een inventarisatie van fysiotherapie bij RSI. Eindverslag Programma Paramedische Zorg (CvZ) 2002. Rotterdam: Afdeling Huisartsgeneeskunde Erasmus Universiteit, 2002.

Takala EP, Viikari-Juntura E, Tynkkynen EM. Does group gymnastics at the workplace help in neck pain? Scand J Rehabil Med 1994; 26: 17-20.

Ekberg K, Bjorkqvist B, Malm P, et al. Controlled two year follow up of rehabilitation for disorders in the neck and shoulders. Occup Environ Med 1994; 51: 833-838.

Schonstein E, Kenny D, Keating J, et al. Physical conditioning programs for workers with back and neck pain. Spine 2003; 28: E391-E395.

Kool J, Bie R de, Oesch P, et al. Exercise reduces sick leave in patients with non-acute non-specific low back pain. J Rehabil Med 2004; 36: 49-62.

Bendix AF, Bendix T, Ostenfeld S, et al. Active treatment programs for patients with chronic low back pain. Eur Spine J 1995; 4: $148-152$.

Skouen JS, Grasdal AL, Haldorsen EM, et al. Relative cost-effectiveness of extensive and light multidisciplinary treatment programs versus treatment as usual for patients with chronic low back pain on long-term sick leave: randomized controlled study. Spine 2002; 27: 901-910.

Hagen EM, Eriksen HR, Ursin H. Does early intervention with a light mobilization program reduce long-term sick leave for low back pain? Spine 2000; 25: 1973-1976.

Storro S, Moen J, Svebak S. Effects on sick-leave of a multidisciplinary rehabilitation programme for chronic low back, neck or shoulder pain: comparison with usual treatment. J Rehab Med 2004; 36: 12-16.

Feuerstein M, Callan-Harris S, Hickey P, et al. Multidisciplinary rehabilitation of chronic work-related upper extremity disorders. J Occup Med 1993; 35: 396-403.

Karjalainen K, Malmivaara A, Tulder M van, et al. Multidisciplinary biopsychosocial rehabilitation for neck and shoulder pain among working age adults. Spine 2001; 26: 174-181.

Karjalainen K, Malmivaara A, Tulder M van, et al. Multidisciplinary biopsychosocial rehabilitation for subacute low back pain in working-age adults. Spine 2001; 26: 262-269.

Guzmán J, Esmail R, Karjalainen K, et al. Multi-disciplinary rehabilitation for chronic low back pain. BMJ 2001; 322: 1511-1516.

Tveito TH, Hysing M, Eriksen HR. Low back pain interventions at the workplace: a systematic literature review. Occup Med 2004; 54: 3-13. 